\section{Through a world of sheep}

\section{Hans-Peter Uerpmann}

Sheep and Man.

By M. L. Ryder.

Duckworth: 1983. Pp.846. £55.

THE sheep - symbolic creature of docility, sacrifice and stupidity. But our psychological assessment of this animal pays scant respect to its enormous economic importance. Not only were sheep among the first animals to be domesticated, they still sustain millions of people with their products of milk, wool and meat.

In Sheep and Man, Michael Ryder has produced a truly comprehensive book which covers every aspect of the historical

IMAGE
UNAVAILABLE
FOR
COPYRIGHT
REASONS

Long, long trail awinding - the traditional rotation of pastures in Switzerland, sheep returning to the valleys after spending summer grazing on the mountains.

development of this particular relationship between man and beast. For archaeologists, for historians and sociologists dealing with rural societies, for ethnologists, for farmers with an interest in history, for veterinarians and to a certain extent also for biologists, this book will be a seemingly inexhaustible mine of information about sheep and their exploitation during prehistoric and historic times. The who, what, when, where, why and how of domestication are dealt with, and the changes after domestication are covered. There is an account of the spread of sheephusbandry from its original centre in southwest Asia towards the Mediterranean and into Europe, and also a long chapter on the sheep of the ancient civilizations.
The first part of the book deals with prehistoric and early historic times, the second part with the period from the Middle Ages to recent times. After dealing with nomadism, transhumance and other types of husbandry systems, Ryder gives a geographical overview, starting with the countries of the Middle East, then passing through Asia, Europe and Africa to the Americas, Australia and New Zealand. Types of sheep, their products and the many different ways to obtain and handle these products are illustrated and described with all the knowledge of a scientist who has devoted most of his work to the history of this animal, and who is able to offer the reader an incredible amount of detail.

The third and final part concentrates the information under more generalized headings: husbandry and sheep products are summarized and the text concludes with a chapter on "The Sheep Legacy", including Ryder's assessment of the future direction of the sheep-man relationship. An appendix with a chronological list of illustrations covering the time between about $5000 \mathrm{BC}$ and the last century is as useful as the vast bibliography, which contains more than a thousand references. An exhaustive index makes the encyclopaedic character of the book complete.

As usual with works such as this, the specialist will cavil at certain points - he will not agree with some generalizations, he may find some details superfluous and others missing. No full account of my own disagreements can be given here, but it would not seriously diminish the value of Sheep and Man. Even the fact that the ideas on the beginnings of sheep domestication have moved on since the pertinent chapters of the book were written, is mitigated by Ryder's complete description of the earlier views. Sometimes, however, confusion is caused when reference to new publications is made in one instance, but not in others referring to the same topic. For example, it is noted on page 14 that the mouflon is now regarded as an early escapee, as a feral animal brought to the Mediterranean islands by Neolithic man as an already domesticated animal. Later, though, the possibility is discussed that the European mouflon might be among the wild ancestors of sheep. In my view most claims of the existence of an indigenous wild sheep in Europe are highly questionable, both with regard to the stratification of the respective finds and to their identification.

It will always be the fate of books with some 800 densely printed pages that their early parts will be somewhat dated when the last word is written. Most of Ryder's book cannot become outdated, however. In its painstaking compilation of facts, Sheep and Man is a feat of scholarship which will itself become a major historical source.

Hans-Peter Uerpmann is at the Institut für Urgeschichte, University of Tubingen.
TWO NEW reliable, up-to-date and complete biotechnology

\section{information resources.}

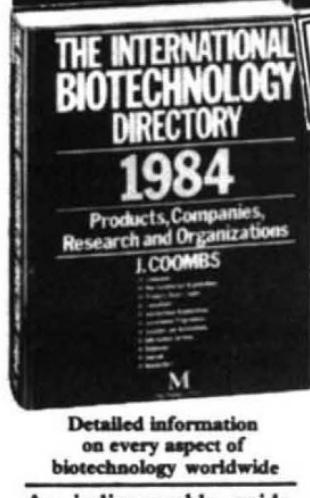

biotechnology worldwide

An indispensable guide to: $\star$ Products, services and research $\star$ Companies $\star$ Government and international agencies $\star$ Infor mation sources

THE INTERNATIONAL BIOTECHNOLOGY DIRECTORY 1984

- is thoroughly international - features a unique BUYER'S GUIDE to products, re search and services

EXAMINE ON FREE APPROVAL FITHOUT COMMITMENT

- covers both the old and new biotechnologies

The Directory tells you: -Who your competition is, and what they are doing. \Who are potential customers and suppliers.

$\star$ Where to buy equipment, chemicals and services.

* Where culture collections are located and what cultures they hold.

\Who imports/exports bioechnology products in over 20 countries.

- Which government de partments are associated with biotechnology.

All compiled by the eminent biotechnologist Dr. Jim Con combs and now available to you on

Macmillan Hardcover 400pp November 1989 ISBN 033335140 [50.00/As100.00

\section{Information \\ Sources in \\ Biotechnology}

- covers both old and new technologies

^ covers technical and com. mercial literature

- covers difficult and hard to trace sources

* includes over 20 at-aglance evaluation tables * provides an Index of publishers and their addresses

Dr. Crafts-Lighty, Head of Information and Library Services at Celtech Limited, systematically and critically reviews all the important information sources:

- books • conferences • trade periodicals $\bullet$ research period-

icals - computer databases

icals - computer databases

- patent - market surveys

- secondary sources

\section{FREE APPROTAL ORDEER FORM}

\section{To: Ian Jacobs, Globe Book The Nature Press,}

Services Lid., FAEEPOST, 15 E 28 Streot, New York,

Bnunel Road, Houndmills,

Basingatoke

Hante RQ21 2BR, England.

$I$ Please send me on 30 days FREE APPROVAL callers call tollifree New York: 212.532-4811)

I copies of The International Biotechnology Directory 1984 at

\$50.00/5100.00 each, and/or copies of Information

Sources in Blotectinology at $\$ 40.00 / 580.00$ each.

I If I am not entirely satisfied. I may return any book in good

I If am not entirely satisfied. I may return any book in good

I Postage and Packing

I UK subscribers £2.00 (Overseas £3.00) US Subscribers

$1 \$ 1.50$

I Tick preferred method of payment

1 $\square$ Bill me. I need send no money now.

1 $\square$ I enclose cheque for $\varepsilon / \$$

1 Charge my credit card on publication $\varepsilon / 5$

1 Visa Access/Mastercharge Am. Express Diners

I Card No.

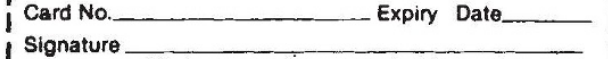

(Orders cannot be accepted without a signature)

Name_____EASE PRINT)

Address

(PLEASEPRINT)

1

Postcodelzip Code

Books will be delivered to you on publication.

UK SUbscribers POST TODAY - NO STAMP NEEDED 